\title{
The Level of Early Childhood Teachers' Knowledge Regarding the Practices of Early Intervention for Children at Risk of Learning Disabilities
}

\author{
Aseel Alshalfan \\ MA Special Education Department, \\ Imam Abdulrahman Bin Faisal University, \\ Dammam, Saudi Arabia \\ Yousef Busaad \\ Assistant professor, \\ Special Education Department, \\ Imam Abdulrahman Bin Faisal University, \\ Dammam, Saudi Arabia
}

DOI: https://doi.org/10.36941/jesr-2022-0020

\begin{abstract}
This study aimed to reveal the level of knowledge of early childhood teachers regarding the early intervention strategies for children at risk of learning disabilities. A questionnaire was designed comprising (22) items distributed in (3) dimensions, namely the practices related to pre-academic skills, basic operations and psychological concepts. This was applied to a random sample of (340) female early childhood teachers. The results indicated a high level of knowledge of early intervention practices in all three dimensions among teachers, and also statistically significant variations in the level of knowledge of early intervention practices attributed to the educational stage which is in favor of the pre-primary stage. The results also showed no statistically significant differences attributable to academic qualification, academic specialization and years of experience. Based on the outcome, the researchers recommended developing training programs to enable early childhood teachers to implement their expertise and utilize it as early intervention methods.
\end{abstract}

Keywords: Early childhood teachers; Early intervention practices; Children at risk of learning disabilities

\section{Introduction}

Early intervention has received considerable attention in recent years due to its preventive and critical function in preventing or mitigating the impacts of disability early in a child's life (Tatweer for Educational Services, 2018). According to several studies, including the study of (Elisheba et al., 2018; Gimenez et al., 2020; Jose and Isaias, 2020), early intervention has a favorable influence on academic achievement, social and emotional adjustment and physical health. This is reflected in the child's future quality of life and the prevention of future academic learning disabilities. The outcome of these studies demonstrated the efficacy of early intervention practices in enhancing the growth of children at risk of learning disabilities and alleviating the negative effects of these difficulties. Hence, 
there is significance in adopting early intervention approaches and providing preventative education programs to support the development of children with disabilities in early childhood, especially those at risk of learning difficulties, is demonstrated (Al-Khatib \& Al-Hadidi, 2021).

In the Kingdom of Saudi Arabia, the diagnosis of students with learning disabilities in the primary stage revealed the presence of some developmental disorders in early childhood. These may predict the risk of developing academic learning disabilities later in life if no early intervention is provided (Al-Adel, 2013). It should be borne in mind that an early childhood teacher's profession is not limited to the teaching process alone.

This fact is supported by the study of (Harithi \& Al-Qahtani, 2020), which revealed the significance of the teacher's role, and that she is an important and critical component of the early intervention process and its activities. As a result of the positive impact of these in mitigating the severity of developmental learning disorders and preventing the risk of academic learning disabilities later in life, it has become necessary to reveal the level of knowledge of early childhood teachers regarding early intervention practices for children at risk of learning disabilities (Oshish, 2020).

\section{Study Problem}

The child's developmental learning disorders will unquestionably have a detrimental impact on numerous elements of his growth, such as academic accomplishment and psychological, personal, and social adjustment, which may later impact his professional adjustment in the future. This fact is confirmed by the study of Fletcher and Grigorenko (2018), which revealed the correlation between basic psychological processes and academic skills. Accordingly, if the early childhood teachers lack sufficient knowledge and experience in early intervention practices, this will have a direct impact on their inability to provide the necessary and early support to children at risk of learning disorders, which will reflect on their future academic skills (Koch, 2011).

Given the scarcity of studies aimed at determining the level of knowledge of early childhood teachers about early intervention practices-within the researcher's knowledge-, the significance of this study lies in revealing the level of knowledge of early childhood teachers concerning early intervention practices for children at risk of learning disabilities in the KSA's eastern region and this by answering the following questions:

What is the level of knowledge of early childhood teachers about early intervention practices for children at risk of learning disabilities in the Eastern Province of Saudi Arabia?

From this question, a group of the following sub-questions emerges:

- Are there statistically significant variations at the significance level (0.05) between the means of early childhood teachers' responses regarding their level of knowledge of early intervention practices for children at risk of learning disabilities attributed to the academic qualification (diploma - bachelor's - master's)?

- Are there statistically significant differences at the significance level (0.05) between the means of early childhood teachers' responses regarding their level of knowledge of early intervention practices for children at risk of learning disabilities attributed to specialization (early childhood - primary classes - other disciplines)?

- Are there statistically significant variations at the significance level (0.05) between the means of early childhood teachers' responses regarding their level of knowledge of early intervention practices for children at risk of learning difficulties attributable to years of experience (below 6 years - 6-10 years - over 10 years)?

- Are there statistically significant differences at the significance level (0.05) between the means of early childhood teachers' responses regarding their level of knowledge of early intervention practices for children at risk of learning difficulties attributable to the teaching stage (kindergarten - preschool - first grade - second grade)? 


\subsection{Study Concepts}

Early intervention practices are the behavior and actions that early childhood teachers utilize to provide early intervention for children with disabilities (Harithi and Al-Qahtani, 2020).

Procedurally, they are defined as the teaching activities and strategies used by kindergarten and primary-school teachers to provide early intervention services to children at risk of learning disabilities, specifically providing activities aimed at developing pre-academic skills, basic psychological processes and psychological concepts.

Children at risk of learning disabilities are those who experience difficulties in pre-academic processes such as attention, cognition, remembering and language which are regarded as the most important foundations on which the individual's mental activity is based, and that any disorder or defect that affects these processes necessarily cause many academic difficulties later (Suleiman, 2019). Procedurally, they are defined as the children who suffer developmental learning disorders exhibited in basic psychological processes (attention, perception, remembering and language), which may result in academic learning challenges later in life.

Early childhood, according to the National Association for the Education of Young Children (NAEYC) and (Brewer, 2006), is the period from birth to the age of 8 years. Procedurally, it is the stage that extends from the age of 3 to 8 years, that is from the beginning of the kindergarten stage until the end of the second grade.

Early childhood teachers are those who have educational qualifications from the College of Education in the Kindergarten Department or the Early Childhood Department (Abdel Rahman, 2020). Procedurally, they are all early childhood teachers from kindergarten to primary grades (first and second grades) and work as teachers in public, private and international schools.

\subsection{Theoretical Framework}

From an educational and psychological standpoint, the earliest years of a child's life are critical in determining their future, and they become much more significant if some indicators of developmental learning disorders arise at this period (Campana et al., 2020). Between the ages of 3 and 8 years, the child goes through various biological stages of basic psychological processes such as thinking and cognition (Abdel-Baqi et al.,2019), which have a significant impact on his later years and serve as the foundation for lifelong learning. This is why we may assume that developmental learning disorders can lead to academic learning challenges later in life if the child is not provided with early intervention programs and practices that are tailored to his specific requirements (Pensova et al.,2014; Shire \& Adam, 2017).

From this standpoint, it is clear the importance of shedding light on the developmental learning disorders that children may suffer in early childhood, which emphasizes the need to pay attention and work to raise the level of knowledge of early intervention practices and their application and adapt the curriculum based on several aspects such as children's needs, age stage, individual differences, and the deficiencies they have in basic psychological processes (Belloural et al., 2017). There is no doubt that the early childhood teacher plays a significant role in the educational process of children since she is the one who communicates the curriculum and adapts the educational environment to the proper learning methods. However, the curriculum will not be useful when it is presented by an unqualified teacher who lacks sufficient knowledge and experience (Fahmy, 2019).

Coppel and Bridkamp (2005/2007) assert that teacher activities and interactions with children in early childhood are the most powerful and developed determinants of learning outcomes. Teachers at this stage also play a significant role in the success, development and progression of the educational program. This requires that teachers of kindergarten and first primary grades possess a variety of skills and knowledge that contribute to the effective planning of daily learning experiences. This particularly concerns students who have been identified as having developmental learning disorders. 
Furthermore, the early childhood teacher's major responsibility is to observe the child and follow up on his growth, especially if she notices some indicators that detect the presence of developmental learning disorders. This is because her role here is to provide early intervention practices based on sound educational foundations tailored to meet the characteristics of each child, and according to their different developmental aspects (Zureikat, 2015). Therefore, we can realize that an early childhood teacher must be well-versed in early intervention strategies for children at risk of learning disabilities to mitigate these developmental difficulties and prevent academic learning disorder that the child may experience later.

\subsection{Previous Studies}

Few studies have been conducted to identify the level of knowledge of early childhood teachers concerning early intervention practices for children at risk of learning difficulties to the best of the researchers' knowledge. However, much significant research undertaken in Arab and international countries addressed the subject of early intervention and its importance for children in early childhood in addition to the pivotal role of teachers in providing activities and strategies related to early detection of children at risk of learning disabilities.

Gjelaj and Zabeli (2020) conducted a study aimed at revealing how preschool teachers understand comprehensive education in early childhood, and which also adopted the qualitative experimental approach on a sample of (10) preschool teachers using the structured and semistructured interview as the main tool. The results revealed a disparity in preschool teachers' understanding of comprehensive education in early childhood. This was in addition to their possession of necessary knowledge and information and their lack of skills in applying and implementing these while managing children with disabilities. Therefore, the study recommended designing high-quality training programs to train teachers to apply early intervention practices related to inclusive education in early childhood.

Al Otaiba et al. (2019) measured teachers' knowledge of response to intervention (RTI) implementation and their understanding of this within their school. The study adopted the descriptive approach and applied a questionnaire to a sample of (139) general and special education teachers. The results showed the low level of teachers' knowledge of the response to the intervention model, and their feeling of unwillingness to apply early intervention practices based on the response to the intervention model. The study recommended the importance of providing professional development for teachers to increase their level of knowledge as this is essential in implementing early intervention programs appropriate to the needs of children with learning difficulties and children at risk. Sheikh (2018) conducted a study to identify the level of knowledge and use of public education teachers of the techniques of applied behavior analysis as one of the activities of early intervention by applying a questionnaire to (40) teachers. The outcome of the study demonstrated that participants possessed the required knowledge of the techniques of desirable behavior, and medium knowledge of the techniques of undesirable behavior, also the use of these techniques was average. In addition to the positive direct relationship between the level of public education female teachers' knowledge of the techniques of behavior analysis and the extent of their use of them, this result explained that increasing female teachers' knowledge of these techniques enhances their awareness of the importance of applying them.

Shafei (2017) also conducted a study aimed at identifying the impact of a suggested electronic training program in developing the competency of kindergarten teachers to develop the capabilities of children with learning disabilities. This study adopted the descriptive and experimental method. The study sample included (35) teachers from kindergartens in Dawadmi Governorate, Kingdom of Saudi Arabia. Several tools were used as an achievement test and an observation form for kindergarten teachers in the first, second and kindergartens stages. The results indicated the efficiency of the proposed program in developing the competencies of female teachers. They also demonstrated the fact that training female teachers on teaching practices and strategies develops 
their abilities, especially in preparing appropriate activities for children and developing their cognitive skills such as attention, perception, memory and thinking. They also showed the teachers' strong need for knowledge and application to achieve their desired benefits from the early intervention.

In the same year, Khawaldeh et al. (2017) conducted a study aimed at revealing the level of knowledge of kindergarten teachers in Jordan about oral language development strategies as an early intervention practice and developing children's readiness for language skills. The study relied on the descriptive approach on a sample of (107) kindergarten teachers Children, using a multiple-choice test tool to achieve the objectives of the study and to reveal the level of knowledge of teachers about these language strategies as one of the practices related to early intervention. The results indicated that the level of knowledge of these strategies was moderate. The study recommended the need to provide programs and courses for kindergarten teachers to enhance their knowledge and application of these teaching strategies. It is evident from the previous studies that the majority study differs from those studies in that it examined the level of knowledge of early childhood teachers concerning early intervention practices for children at risk of learning disabilities in particular, rather than in general, as previous studies did.

\section{Methods and Procedures}

\subsection{Study Approach}

Considering the nature and objectives of the current study, the descriptive survey method was adopted to identify the level of knowledge of early childhood teachers regarding early intervention practices for children at risk of learning disabilities. As it is known, the survey approach seeks to study and describe the phenomenon accurately through quantitative and qualitative expression (Obeidat et al., 2016).

\subsection{Population and Sample}

The study population comprised all the (1895) female early childhood teachers in the cities of Khobar, Dhahran and Dammam in the Kingdom of Saudi Arabia's Eastern Province according to the statistics of the Planning and Development Department of the General Administration of Education in the Eastern Province (2021). The study sample comprised (340) female early childhood teachers who were chosen randomly, representing $18 \%$ of the study population as shown in Table (1).

Table 1: Description of the study sample according to its independent variables

\begin{tabular}{|l|c|c|c|}
\hline Independent Variables & Level & Frequency & Percentage \\
\hline Academic Level & Diploma & 42 & $\% 12.4$ \\
\cline { 2 - 4 } & Bachelor & 284 & $\% 83.5$ \\
\cline { 2 - 4 } & M.A. & 14 & $\% 4.1$ \\
\hline \multirow{3}{*}{ Specialization } & Early childhood & 148 & $\% 43.5$ \\
\cline { 2 - 4 } & Primary classes & 40 & $\% 11.8$ \\
\cline { 2 - 4 } & Other majors & 152 & $\% 44.7$ \\
\hline Years of Experience & Less than 6 years old & 158 & $\% 46.5$ \\
\cline { 2 - 4 } & From 6 to 10 years & 76 & $\% 31.2$ \\
\cline { 2 - 4 } & Above than 10 years & 106 & $\% 32.4$ \\
\hline \multirow{3}{*}{ Education Stage } & KG 1 & 110 & $\% 28.8$ \\
\cline { 2 - 4 } & KG2 & 98 & $\% 18.2$ \\
\cline { 2 - 4 } & First grade & 62 & $\% 20.6$ \\
\cline { 2 - 4 } & Second grade & 340 & $100 \%$ \\
\hline
\end{tabular}




\subsection{Study Tool}

To achieve the goal of the study, a two-part questionnaire was designed, the first part included the general data of the participants, while the second part measures the level of female teachers' knowledge of early intervention practices in three main dimensions, the first dimension seeks to measure the level of female teachers' knowledge of early intervention practices related to the development of pre-academic skills including (8) items, and the second dimension measures the level of female teachers' knowledge of the practices of early intervention related to the development of basic processes through (7) items, and the third dimension measures the level of knowledge of female teachers regarding early intervention practices related to the development of psychological concepts including (7) items. A four-point Likert scale was used (I do not have any knowledge, I have low knowledge, I have no medium knowledge, I have high knowledge). Ethical considerations were also considered by assuring the study participants that all data will be strictly confidential and will be used only for scientific research purposes.

\subsection{Tool Validity and Reliability}

To check the face validity of the questionnaire, it was presented to a group of experts specialized in the fields of special education in learning disabilities and early childhood education for arbitration regarding clarity of phrases and their relevance. Based on the feedback obtained from experienced arbitrators, some items were reformulated and added after applying the questionnaire to an exploratory sample of (74) early childhood teachers. The researchers used Cronbach's Alpha reliability coefficient for extracting the reliability of the features of the questionnaire and its overall reliability. Pearson's correlation coefficient was applied to examine the correlation of the items with the dimensions to which they belong to confirm the construct validity of the questionnaire as shown in Tables (2) and (3).

Table (2) shows that the correlation coefficients of the items with their dependent dimensions are significant correlations at a significance level of (o.o1) which indicates a high construct validity of the dimensions of the questionnaire. The items affiliated with the total mean of the dimension responses are true statements that measure for what they were developed. To assure that the dimension is related to the overall mean of the questionnaire, the correlation coefficients of the means of the responses on the dimensions with the overall mean of the questionnaire were calculated. Table (3) shows the correlation coefficients for the dimensions with the overall tool.

Table 2: Indicators of the tool construct validity

\begin{tabular}{cccccc}
\hline & First dimension & \multicolumn{2}{c}{ Second dimension } & \multicolumn{2}{c}{ Third dimension } \\
\hline Items & correlation coefficient & Items & correlation coefficient & Items & correlation coefficient \\
\hline $\mathbf{1}$ & $0.610^{* *}$ & 1 & $0.789^{* *}$ & 1 & $0.842^{* *}$ \\
\hline $\mathbf{2}$ & $0.720^{* *}$ & 2 & $0.766^{* *}$ & 2 & $0.824^{* *}$ \\
\hline $\mathbf{3}$ & $0.688^{* *}$ & 3 & $0.848^{* *}$ & 3 & $0.837^{* *}$ \\
\hline $\mathbf{4}$ & $0.726^{* *}$ & 4 & $0.845^{* *}$ & 4 & $0.849^{* *}$ \\
\hline $\mathbf{5}$ & $0.710^{* *}$ & 5 & $0.819^{* *}$ & 5 & $0.718^{* *}$ \\
\hline $\mathbf{7}$ & $0.797^{* *}$ & 6 & $0.718^{* *}$ & 6 & $0.845^{* *}$ \\
\hline $\mathbf{8}$ & $0.799^{* *}$ & 7 & $0.836^{* *}$ & 7 & $0.763^{* *}$ \\
\hline$* *$ Statistically significant at $(0.05)$ & - & - & - & - \\
\hline
\end{tabular}

Table 3: The correlation coefficients of the dimensions of the tool with its overall mean

\begin{tabular}{|c|c|}
\hline Dimensions & correlation coefficient \\
\hline 1 Early intervention practices related to pre-academic skill development & $0.890^{* *}$ \\
\hline 2 Early intervention practices related to the development of basic operations & $0.915^{* *}$ \\
\hline 3 Early intervention practices related to the development of psychological concepts & $0.922^{* *}$ \\
\hline
\end{tabular}


Table (3) shows that the correlation coefficients of the dimensions with the overall mean of the questionnaire are statistically significant at a significance level of (o.o1) or less, and the high correlation coefficients are evidence of the high construct validity of the questionnaire.

Table 4: Cronbach's alpha reliability coefficient for overall reliability and questionnaire dimensions

\begin{tabular}{clc}
\hline & \multicolumn{1}{c}{ Dimensions } & Cronbach's coefficient \\
\hline $\mathbf{1}$ & $\begin{array}{l}\text { Early intervention practices related to pre-academic skill } \\
\text { development }\end{array}$ & 0.86 \\
\hline $\mathbf{2}$ & $\begin{array}{l}\text { Early intervention practices related to the development } \\
\text { of basic operations }\end{array}$ & 0.90 \\
\hline $\mathbf{3}$ & $\begin{array}{l}\text { Early intervention practices related to the development } \\
\text { of psychological concepts }\end{array}$ & 0.91 \\
\hline $\mathbf{4}$ & Overall reliability & 0.95 \\
\hline **Statistically significant at $(0.05)$
\end{tabular}

By examining the Cronbach's Alpha reliability coefficients in Table (4), we notice that the questionnaire has excellent reliability coefficients (o.86-0.95) as classified by (Taber, 2016) which makes it valid to achieve the objectives of the study.

\subsection{Procedures}

The study was approved after the Department of Special Education at Imam Abdulrahman Bin Faisal University reviewed its details and procedures. The approval was obtained by the General Administration of Education in the Eastern Region represented by the Department of Planning and Development to circulate the questionnaire to the target sample. It was also posted to the supervisors of the General Administration of Education in the Eastern Province to be circulated to school leaders in Khobar, Dhahran and Dammam to reach the target group. This group comprises kindergarten teachers and first and second-grade teachers in public, private and international schools affiliated to the Ministry of Education, and (340) questionnaires were valid for statistical analysis. It should be noted that all the respondents agreed to participate in the study before they started the questionnaire. To determine the rating scale of the questionnaire, the 4-point Likert scale was used for calculating the range $\left(4^{-1}=3\right)$ and then dividing it by the largest value in the scale which is $(4=$ $0.75 \div 3$ ), and then this value was added to the lowest value in the scale (The beginning of the scale, which is 1 ) to determine the upper limit of this cell. The range of all the dimensions are shown in Table (5).

Table 5: Distribution of alternatives according to the grading used in the questionnaire

\begin{tabular}{lcccc}
\hline Knowledge degree & Do not any knowledge & Low & Medium & high \\
\hline Values & 1 & 2 & 3 & 4 \\
\hline Ranges & less than 1.75 & $(1.75-2.5)$ & $(2.5-3.25)$ & $(3.25-4)$ \\
\hline
\end{tabular}

\subsection{Statistical Methods}

The data were processed using the statistical package (SPSS) method to analyze the results using descriptive statistics methods such as frequencies, percentages, arithmetic means and standard deviations. Inferential statistics methods were used such as Pearson correlation coefficient, Cronbach's Alpha coefficient and the ANOVA analysis followed by Post Hoc Comparisons (Scheffe). 


\section{Results and Discussion}

\subsection{Result of the main question}

What is the level of knowledge of early childhood teachers of early intervention practices for children at risk of learning disabilities in the Eastern Province of Saudi Arabia? This is to identify the level of knowledge of early childhood teachers of early intervention practices for children at risk of learning disabilities in early childhood. It also involves the means, standard deviations and level of the responses on the dimensions of early childhood teachers' knowledge of early intervention practices for children at risk of learning difficulties, as well as the as shown in Table (6).

Table 6: The level of knowledge of teachers of early intervention practices for children at risk of learning disabilities

\begin{tabular}{llllll}
\hline NO. Item & \multicolumn{3}{c}{ Mean SD } & Rank Level \\
\hline $\mathbf{2}$ & Early intervention practices related to the development of basic operations & 3.43 & 0.71 & 1 & High \\
\hline $\mathbf{3}$ & Early intervention practices related to the development of psychological concepts & 3.39 & 0.72 & 2 & High \\
\hline $\mathbf{1}$ & Early intervention practices related to pre-academic skill development & 3.34 & 0.71 & 3 & High \\
\hline Total & 3.38 & $0.71-$ & High \\
\hline
\end{tabular}

Table (6) illustrates that the level of knowledge of early childhood teachers about early intervention practices for children at risk of learning difficulties in early childhood came with a (high) degree and a mean of (3.38). Considering the responses of the participants regarding the level of knowledge of early childhood teachers about early intervention practices for children at risk of learning difficulties in early childhood, the data in Table (6) indicated that the second dimension (early intervention practices related to the development of basic processes) ranked first with a mean (3.43) and (high)degree followed by the third dimension (early intervention practices related to the development of psychological concepts) with a mean (3.39) and a (high) degree. While the dimension (early intervention practices related to the development of pre-academic skills) obtained a mean of (3.34) and a (high) degree.

Based on the aforementioned results, the level of knowledge of teachers of early intervention practices for children at risk of learning disabilities in early childhood shows a high degree of knowledge in all three dimensions. This can be interpreted by the fact that a large percentage of kindergarten and primary school teachers have a sense of responsibility. This led to their continuous access to educational references related to children, and the features regarding their development as well as reviewing scientific sources on educational and teaching strategies. Furthermore, it can be attributed to the efforts made by the Ministry of Education represented by kindergartens and primary schools (governmental, private and international) through the provision of training programs to promote the level of female teachers' knowledge of early childhood educational practices and activities. Moreover, we find that some schools require new female teachers to join a summer training program before starting work. This aims to train them in the methods and activities used when working with children, and on the steps of the daily program, including teaching methods and educational strategies to be used with children.

Female teachers' possession of high knowledge regarding early intervention practices is undoubtedly a positive outcome, this emphasizes the significance of determining the extent to which they possess the requisite abilities for the appropriate intervention and to reduce the exacerbation of developmental disorder before influencing the children's scholastic performance in the primary stage.

Abu Nyan (2021) states that the percentage of students with learning disabilities constitutes $7 \%$ of the students in schools which confirms the need for early intervention programs to support these students. Hence, the results of the study of (Khawaldeh et al., 2017 \& Shafei, 2017) confirm that female teachers need extensive training to use the knowledge they possess concerning early intervention practices in the field of early childhood, particularly the appropriate activities for children at risk of learning disabilities.

Gjelaj and Zabeli (2020) also recommend designing high-quality programs targeting the 
practical side of early intervention practices because this training develops their abilities to design and implement appropriate activities and strategies for their children. This contributes to mitigating the developmental learning disorders from which children suffer in early childhood. The teaching methods, practical practices and strategies used by teachers are essential elements in the early intervention process for children at risk of learning difficulties (Al-Zuman, 2020).

\subsection{Results of the first question}

Are there statistically significant differences at the significance level (0.05) between the means of early childhood teachers' responses regarding their level of knowledge of early intervention practices for children at risk of learning disabilities attributed to the academic qualification (diploma bachelor's - master's)?

To address this question, the ANOVA was used to find the statistical variations between the responses of parameters in the dimensions of the questionnaire as in Table (7).

Table 7: ANOVA test for participants' responses in the first, second and third dimensions due to the educational qualification variable

\begin{tabular}{|c|c|c|c|c|c|c|}
\hline Dimension & Source of variance & SS & DF & MS & F value & Total value \\
\hline \multirow{3}{*}{ First } & Between groups & 0.499 & 2 & 0.250 & \multirow{3}{*}{0.459} & \multirow{3}{*}{0.610} \\
\hline & Within groups & 170.164 & 337 & 0.505 & & \\
\hline & Total & 170.663 & 339 & - & & \\
\hline \multirow{3}{*}{ Second } & Between groups & 0.878 & 2 & 0.439 & \multirow{3}{*}{0.868} & \multirow{3}{*}{0.421} \\
\hline & Within groups & 170.488 & 337 & 0.506 & & \\
\hline & Total & 171.366 & 339 & - & & \\
\hline \multirow{3}{*}{ Third } & Between groups & 0.245 & 2 & 0.122 & \multirow{3}{*}{0.233} & \multirow{3}{*}{0.792} \\
\hline & Within groups & 177.134 & 337 & 0.526 & & \\
\hline & Total & $177 \cdot 379$ & 339 & - & & \\
\hline \multirow{3}{*}{ All practices } & Between groups & 0.454 & 2 & 0.227 & \multirow{3}{*}{0.501} & \multirow{3}{*}{0.606} \\
\hline & Within groups & 152.656 & 337 & 0.453 & & \\
\hline & Total & 153.110 & 339 & - & & \\
\hline
\end{tabular}

Table (7) shows no statistically significant diversity at the significance level (0.05) or less between the teachers' responses regarding their level of knowledge of early intervention practices for children at risk of learning difficulties in the Eastern Province in all dimensions, and in all activities attributed to the scientific qualification (diploma, bachelor's, master's). This result can be attributed to the fact that several female teachers participating in the study have a bachelor's degree and possess extensive knowledge of early intervention practices as a result of the high quality of study programs offered to them at the various educational colleges from which they graduated.

In this context, Shafei (2017) emphasized the impact of developing the plans of the courses offered in each college concerning early intervention, Sheikh (2018) also mentioned the positive direct relationship between the increase in the knowledge levels of female teachers and the extent to which they use and apply such methods. Moreover, many teachers who have been involved in this study have a master's in educational disciplines and possess the cognitive competencies to work with children at the early childhood stage.

\subsection{Results of the second question}

Are there statistically significant differences at the significance level (0.05) between the means of early childhood teachers' responses regarding their level of knowledge of early intervention practices for children at risk of learning disabilities attributed to specialization (early childhood - primary classes - other disciplines)? 
To address the question, ANOVA was used to find the statistical variations between the responses of participants in the dimensions of the questionnaire as illustrated in Table (8).

Table 8: ANOVA test for the responses of the participants in the first, second and third dimensions according to the specialization variable

\begin{tabular}{|c|c|c|c|c|c|c|}
\hline Dimension & Source of variance & SS & DF & MS & F value & Total value \\
\hline \multirow{3}{*}{ First } & Between groups & 0.421 & 2 & 0.211 & \multirow{3}{*}{0.417} & \multirow{3}{*}{0.659} \\
\hline & Within groups & 170.242 & 337 & 0.505 & & \\
\hline & Total & 170.663 & 339 & - & & \\
\hline \multirow{3}{*}{ Second } & Between groups & 0.253 & 2 & 0.126 & \multirow{3}{*}{0.249} & \multirow{3}{*}{0.78} \\
\hline & Within groups & 171.113 & 337 & 0.508 & & \\
\hline & Total & 171.366 & 339 & - & & \\
\hline \multirow{3}{*}{ Third } & Between groups & 1.317 & 2 & 0.659 & \multirow{3}{*}{1.261} & \multirow{3}{*}{0.285} \\
\hline & Within groups & 176.062 & 337 & 0.522 & & \\
\hline & Total & $177 \cdot 379$ & 339 & - & & \\
\hline \multirow{3}{*}{ All practices } & Between groups & 0.508 & 2 & 0.254 & \multirow{3}{*}{0.56} & \multirow{3}{*}{0.571} \\
\hline & Within groups & 152.603 & 337 & 0.453 & & \\
\hline & Total & 153.11 & 339 & - & & \\
\hline
\end{tabular}

The results in Table (8) illustrate that there are no statistically significant variations at the significance level (0.05) or less between the teachers' responses regarding their level of knowledge of early intervention practices for children at risk of learning difficulties in the Eastern Region in all dimensions, and in all activities attributed to the specialization of the teacher (early childhood, primary grades, other majors). This result can be explained by the fact that the majority of the participants have an educational qualification or have graduated from educational colleges which has contributed to their increased level of knowledge because they attended educational courses which applied various practical methods utilized with children.

This may also be interpreted by the fact that academic disciplines do not affect the level of knowledge as each teacher may have the skills of research and self-information in the field of early childhood. This is consistent with what (Alotaiba et al., 2019) indicate, as they emphasize the need for professional development for female teachers to raise the level of their knowledge and application of early intervention practices and programs with children at risk of learning disabilities.

\subsection{Results of the third question}

Are there statistically significant differences at the significance level (0.05) between the means of early childhood teachers' responses regarding their level of knowledge of early intervention practices for children at risk of learning difficulties attributable to years of experience (below 6 years - 6-10 years - over 10 years)?

To answer the question, the ANOVA was used to find statistical variations between the responses on the dimensions of the questionnaire as in Table (9).

Table 9: ANOVA test for participants' responses in the first, second and third dimensions according to the variable years of experience

\begin{tabular}{|c|c|c|c|c|c|c|}
\hline Dimension & Source of variance & SS & DF & MS & F value & Total value \\
\hline & Between groups & 0.944 & 2 & 0.472 & \multirow{3}{*}{0.938} & \multirow{3}{*}{0.393} \\
\hline \multirow[t]{2}{*}{ First } & Within groups & 169.719 & 337 & 0.504 & & \\
\hline & Total & 170.663 & 339 & - & & \\
\hline \multirow{3}{*}{ Second } & Between groups & 1.046 & 2 & 0.523 & \multirow{3}{*}{1.035} & \multirow{3}{*}{0.356} \\
\hline & Within groups & 170.320 & 337 & 0.505 & & \\
\hline & Total & 171.366 & 339 & - & & \\
\hline
\end{tabular}




\begin{tabular}{|c|c|c|c|c|c|c|}
\hline Dimension & Source of variance & SS & DF & MS & F value & Total value \\
\hline \multirow{3}{*}{ Third } & Between groups & 1.662 & 2 & 0.831 & \multirow{3}{*}{1.549} & \multirow{3}{*}{0.205} \\
\hline & Within groups & $175 \cdot 717$ & 337 & 0.521 & & \\
\hline & Total & $177 \cdot 379$ & 339 & - & & \\
\hline \multirow{3}{*}{ All practices } & Between groups & 1.143 & 2 & 0.571 & \multirow{3}{*}{1.267} & \multirow{3}{*}{0.283} \\
\hline & Within groups & 151.968 & 337 & 0.451 & & \\
\hline & Total & 153.110 & 339 & - & & \\
\hline
\end{tabular}

The data in Table (9) demonstrates that there are no statistically significant differences at the significance level (o.05) or less between the teachers' responses concerning their level of knowledge of early intervention practices for children at risk of learning disabilities in the Eastern Province in all dimensions and all activities attributed to years of experience (below 6 years, 6-10 years, over 10 years). This can be attributed to the fact that the majority of the participating teachers had less than 6 years' experience in the field of early childhood. This means that they are recent graduates and still enthusiastic and possess the knowledge they studied at university regarding the practices used with children in early years. Furthermore, a significant percentage of the participating teachers have over 10-year experience in the field of early childhood. This demonstrates that working with children helped them to know their characteristics as well as appropriate methods and activities to be used with them. It is worth noting that the current study's outcomes conflict with those of a previous study (Fawzan,2019) which found statistically significant variations in the teachers' level of understanding of the importance of early intervention attributable to years of experience.

\subsection{Results of the fourth question}

Are there statistically significant variation at the significance level (0.05) between the means of early childhood teachers' responses regarding their level of knowledge of early intervention practices for children at risk of learning difficulties attributable to the teaching stage (kindergarten - preschool first grade - second grade)?

The ANOVA test was applied to detect the statistical diversity between the responses of the participants on the dimensions of the questionnaire as depicted in Table (10).

By examining Table (10), it is obvious that there are no statistically significant variations at the significance level (0.05) or less between the teachers' responses regarding their level of knowledge of early intervention practices for children at risk of learning disabilities in the Eastern Region in the second dimension attributed to the educational stage (kindergarten, $\mathrm{KG}_{2}$, first grade, second grade).

Table 10: ANOVA test for participant responses on the first, second, and third dimensions according to educational stage variable

\begin{tabular}{|c|c|c|c|c|c|c|}
\hline Dimension & Source of variance & SS & DF & MS & F value & Total value \\
\hline \multirow{3}{*}{ First } & Between groups & 4.772 & 3 & 1.591 & \multirow{3}{*}{3.222} & \multirow{3}{*}{$0.023^{*}$} \\
\hline & Within groups & 165.892 & 336 & 0.494 & & \\
\hline & Total & 170.663 & 339 & - & & \\
\hline \multirow{3}{*}{ Second } & Between groups & 3.808 & 3 & 1.269 & \multirow{3}{*}{2.546} & \multirow{3}{*}{0.066} \\
\hline & Within groups & 167.557 & 336 & 0.499 & & \\
\hline & Total & 171.366 & 339 & - & & \\
\hline \multirow{3}{*}{ Third } & Between groups & 5.506 & 3 & 1.835 & \multirow{3}{*}{3.588} & \multirow{3}{*}{$0.014^{*}$} \\
\hline & Within groups & 171.872 & 336 & 0.512 & & \\
\hline & Total & 177.379 & 339 & - & & \\
\hline \multirow{3}{*}{ All practices } & Between groups & 4.563 & 3 & 1.521 & \multirow{3}{*}{3.440} & \multirow{3}{*}{$0.017^{*}$} \\
\hline & Within groups & 148.548 & 336 & 0.442 & & \\
\hline & Total & 153.110 & 339 & - & & \\
\hline
\end{tabular}

*Statistically significant at (0.05) or less. 
However, it is clear that there are statistically significant differences in the first and third dimensions and in all activities. To determine the direction of the variation, Scheffe's test was used as shown in Table (11).

Table 11: Schiffer's test to determine the differences between the responses according to the variable of the educational stage

\begin{tabular}{|c|c|c|c|c|c|c|c|}
\hline \multirow{2}{*}{ Dimension } & \multirow{2}{*}{ Educational Stage } & \multirow{2}{*}{ NO. } & \multirow{2}{*}{ Mean } & \multicolumn{4}{|c|}{ Means Comparisons } \\
\hline & & & & KG1 & KG2 & Grade 1 & Grade 2 \\
\hline \multirow{4}{*}{ First } & KG 1 & 110 & $3 \cdot 355$ & - & 0.137 & 0.080 & 0.192 \\
\hline & $\mathrm{KG}_{2}$ & 98 & 3.492 & 0.137 & - & 0.218 & $0.329^{*}$ \\
\hline & Grade 1 & 62 & 3.274 & 0.080 & 0.218 & - & 0.111 \\
\hline & Grade 2 & 70 & 3.163 & 0.192 & $0.329^{*}$ & 0.111 & - \\
\hline \multirow{4}{*}{ Third } & KG 1 & 110 & 3.375 & - & 0.196 & 0.064 & 0.148 \\
\hline & KG2 & 98 & $3 \cdot 571$ & 0.196 & - & 0.260 & $0.344^{*}$ \\
\hline & Grade 1 & 62 & $3 \cdot 311$ & 0.064 & 0.260 & - & 0.084 \\
\hline & Grade 2 & 70 & 3.227 & 0.148 & $0.344^{*}$ & 0.084 & - \\
\hline \multirow{4}{*}{ All practices } & KG 1 & 110 & $3 \cdot 380$ & - & 0.166 & 0.079 & 0.144 \\
\hline & KG2 & 98 & 3.546 & 0.166 & - & 0.246 & $0.310^{*}$ \\
\hline & Grade 1 & 62 & $3 \cdot 300$ & 0.079 & 0.246 & - & 0.064 \\
\hline & Grade 2 & 70 & 3.235 & 0.144 & $0.310^{*}$ & 0.064 & 0.192 \\
\hline
\end{tabular}

*Statistically significant at (o.05) or less.

Regarding the difference between the means of the categories of the educational stage, Table (11) shows that it is statistically significant in the first dimension, but that the variation is between the means of knowledge of the KGs teachers and the teachers of the second grade, where the direction of the diversity is clear through the greater level of knowledge of early intervention practices related to pre-academic skill development for children at risk of learning disabilities for preschool teachers.

Table (11) also shows that the variation between the means of the categories of the educational stage is statistically significant in the third dimension as the difference is between the means of the level of knowledge of the KGs teachers and the second-grade teachers. However, the direction of the variation is evident through the greater knowledge level of early intervention practices related to the development of psychological concepts for children at risk of learning disorders for KGs teachers. On the other hand, Table (11) shows that the variation between the means of the categories of the educational stage is statistically significant in all activities. Furthermore, it is obvious that the means regarding the knowledge of the KGs teachers and the second grade differ. This applies where the direction of the difference is clear through the greater level of knowledge of early intervention practices as a whole for children at risk for learning disorder among teachers of the preschool stage. This is due to the fact that most participating teachers work in the pre-primary stage which influenced the responses favorably. This is confirmed by Gjelaj and Zabeli's (2020) study, which showed the importance of training teachers, employing their knowledge and applying those practices with children in early childhood. This also considered that some of the participating teachers have considerable knowledge. However, they may face challenges which hinder the implementation of these activities, such as the shortage of staff and the large number of children in the classroom (Harithi and Al-Qahtani, 2020), and which may affect their application of early intervention practices. This is apart from the weak effectiveness of the programs' early intervention which targets children at risk of learning difficulties and seeks to mitigate their exacerbation at a later stage.

\section{Conclusion}

As a matter of fact, an early childhood teacher's profession extends beyond the process of teaching children to the process of providing aid to overcome developmental disorders which children may 
experience at a young age. This is through the teacher's knowledge and application of early intervention practices related to the development of pre-academic skills, basic operations and psychological concepts (Khatib and Al Hadidi, 2021).

The current study, therefore, sought to identify the level of knowledge of early childhood teachers regarding early intervention practices for children at risk of learning disabilities in the Eastern Province of Saudi Arabia. In this case, the findings revealed that the mean of responses of the teachers revealed a high level of knowledge of early intervention practices. They also indicated statistically significant variations between the level of knowledge of the teachers in early intervention practices attributed to the educational stage in which the teacher works where it favors the teachers of the KG stage. The results also revealed no statistically significant differences attributed to academic qualification, academic major and years of experience.

\subsection{Study Restrictions}

Due to the circumstances under which the study was prepared, namely the Corona pandemic (Covid19), there was difficulty in circulating and publishing the questionnaire for a large segment of female teachers and directly reaching them in kindergartens, public, private and international schools. This is because the learning mechanism had been changed from traditional learning to distance learning.

\section{Recommendations}

Considering the findings of the study, the researchers recommended the following:

- Designing practical training programs for early childhood teachers (kindergarten, basic grades) to empower and deploy their cognitive capabilities for early intervention for children who may exhibit indications and manifestations of developmental learning disorders.

- Developing and adapting study plans in educational programs to include practical courses that allow students to utilize their classroom knowledge in line with the practical experience they obtain while teaching.

- Creating a broad educational information base to empower female teachers with evidencebased methods and early intervention strategies.

\subsection{Proposals}

In view of the results that demonstrate a high knowledge of early intervention practices among early childhood teachers, the researchers propose to conduct survey studies to reveal the reality of teachers' application of early intervention practices with children at risk of learning difficulties who may have indicators of developmental learning disorders. She also suggests conducting research to identify the aspects that may hinder the application of early intervention practices and reveal the level of awareness of teachers of the importance and effectiveness of early intervention in mitigating developmental learning difficulties to preventing academic learning disabilities.

\section{References}

Abu Nyan, I. (2021). Learning difficulties from history to services. Encyclopedia House.

Abdel Rahman, N. (2020). Awareness of early childhood teachers with augmented reality technology and a proposed vision for its application in early childhood: a field study. Journal of Early Childhood Studies, (14), $185-119$.

Abdel-Baqi, S., Rashid, A., Abdel-Qader, R., Ismail, S., Farag, A., Al-Azhari, M., Zidan, H., Ibrahim, M., \& Riyad, S. (2019). Education in early childhood programs in light of the developmentally appropriate curriculum. Al Mutanabbi Library. 
Al-Adel, A. (2013). Learning difficulties and the impact of early intervention and educational integration for people with special needs. Modern Book House.

Alotaiba, S., Baker, K., Lan, P., Allor, J., Rivas, B., Yovanoff, P., \& Kamata, A. (2019). Elementary teacher's knowledge of response to intervention implementation: A preliminary factor analysis. Annals of Dyslexia, 69, 34-53. https://dx.doi.org/10.1007\%2Fs11881-018-00171-5

Belloural, F., Bartolo, P., Kyriazopoulou, M., \& Staff, A. (2017). Inclusive early childhood education. European Agency for Special Needs and Inclusive Education.

Brewer, J. (2006). Early childhood education. Person Education.

Campana, J., Galisteo, R., Manzanares, L., Ruiz, G., \& Morales, M. (2020). The inventory of quality in early intervention centres for service providers: Preliminary Validating Study in a Spanish Sample. International Journal of Environmental Research and Public Health, 17 (7), DOI: 10.3390/ijerph17072581.

Elisheba W, Kiru., Christian, D., Audrey M, Sorrells., \& North A, Cooc. (2018). A synthesis of technology-mediated mathematics intervention for the student with or at risk for a mathematics learning disability. Journal of Special Education, 33 (2),111-123. Doi: 10.1177/0162643417745835

Fahmy, A. (2019). Kindergarten teacher. (Ed.8). Dar Almasyreh

Fawzan, R. (2019). The role of kindergarten in early intervention for children with indicators of learning difficulties from the point of view of their teachers in Al-Ahsa. Journal of the College of Education, 35(10), 97-121. . Doi: 10.21608/MFES.2019.102441

Fletcher, J, M., \& Grigorenko, E, M. (2018). Neuropsychology of learning disabilities: The past and the future. Journal Int Neuropsychol, 23 (9-10), 930-940. Doi:10.1017/S1355617717001084.

Gimenez, A., Bordoy, S., Sanchez, A., Lopez, Z., Sopena, J., \& Luque, J. (2020). A supplemental computer-assisted intervention programme to prevent early reading difficulties in Spanish learners: A stratified random control trial. Journal of Computer Assisted Learning, DOI: 10.1111/jcal.12504.

Harithi, K.,\& Al-Qahtani, F. (2020). Effective practices of special education teachers in early intervention programs for children with intellectual disabilities: challenges and solutions. The Saudi Journal of Special Education, (15), 141-184. Doi: 10.33948/1640-0oo-015-004.

Jose, M., \& Isaias, M. (2020). Effects of early intervention on the writing skills of pupils who present a risk of learning disabilities within Spain's early years and primary education system. Revista De Education, (388), 85-106. Doi: 10.4438/1988-592X-RE-2020-388-448.

Khatib, J., \& Al-Hadidi, M. (2021). Early Intervention and Special Education in Early Childhood (Ed.11). Dar Alfikker.

Khawaldeh, M., Maqableh, N., Khudair, R., \& Yassin, M. (2017). The level of knowledge of kindergarten teachers in Jordan about strategies for developing oral language, Educational Sciences Studies, 44(4), 241-258. Doi: 10.35516/0102-044-991-016.

Koble, C., \& Bredekamp, S. (2011). Developmentally Appropriate Practice in Early Childhood Programs (Arab Bureau of Education for the Gulf States, translator). (Original work published in 2009).

Koch, K, A. (2011) Dual Role: parent and teacher of children with disabilities. College of Norte Dame of Maryland.

Ministry of Education, Tatweer Company for Educational Services. (2018). Guides for comprehensive education in the Kingdom of Saudi Arabia. Riyadh: Ministry of Education.

Obeidat, T., Abdel Haq, K., \& Adas, A. (2016). Scientific Research Concept, Tools and Methods (I.18). Dar Alfikker.

Oshish, N. (2020). Suggesting a training program for early intervention to treat developmental learning difficulties among pre-school children and studying its effectiveness in preventing academic learning difficulties. Journal of Studies in the Humanities and Social Sciences, 3 (26), 334-353 Doi:10.33953/0381-003-003-017.

Pensova, B., Sivevska, D., \& Runceva, J. (2014). Early intervention and prevention of students with specific learning disabilities. Journal of Social and Behavioral Sciences (149), 701-708. DOI:10.1016/j.sbspro.2014.08.259

Shafei, R. (2017). A proposed electronic training program to develop the competencies of kindergarten teachers to develop the capabilities of children with learning difficulties in the light of the objectives of early intervention, Scientific Journal of the College of Early Childhood Education, 3(4), 635-756.

Sheikh, A. (2018). The level of knowledge and use of parameters for the techniques of applied behaviour analysis in the integration programs in the city of Riyadh. Journal of Scientific Research in Education, 13(19), 175-199. . Doi: 10.21608/JSRE.2019.28341

Shire, A., \& Adam, J. (2017). Working in early childhood programs. Goldfields-Esperance Development Commission.

Suleiman, N. (2019). A program based on the sensory integration strategy in developing pre-academic arithmetic skills for kindergarten children at risk of learning difficulties, Journal of Special Education, 8 (28), 317-279.

Taber, K, S. (2016). The use of Cronbach's alpha when developing and reporting research instruments in science education. Research in Science Education, 48(6), 1273-1296. 
Zabeli, N., \& Gjelaj, M. (2020). Preschool teacher's awareness, attitudes, and challenges towards inclusive early childhood education: A qualitative study. Cogent Education, 7(1). https://doi.org/10.108o/2331186X.2020.179156o.

Zuman, A. (2020). The importance of early intervention for people with learning difficulties in kindergarten and its impact on their academic compatibility. Journal of the College of Education, 20 (2), 221-257.

Zureikat, I. (2015). Early Intervention Models and Procedures (Ed.4). Dar Almasyreh. 